\title{
Metodologia do design educacional no desenvolvimento de sequências de ensino e aprendizagem no ensino de física
}

Educational design methodology in the development of teaching and learning sequences in physics teaching

\author{
Lucas Mesquita*1] $^{*}$ Guilherme Brockington ${ }^{2}$, Leonardo André Testoni ${ }^{1}$, Nelson Studart \\ ${ }^{1}$ Universidade Federal de São Paulo, Programa de Pós-Graduação em Ensino de Ciências e Matemática, Diadema, \\ SP, Brasil. \\ ${ }^{2}$ Universidade Federal do ABC, Centro de Ciências Naturais e Humanas, Santo André, SP, Brasil. \\ ${ }^{3}$ Universidade Federal de São Carlos, Departamento de Física, São Carlos, SP, Brasil.
}

Recebido em 16 de outubro de 2020. Revisado em 27 de janeiro de 2021. Aceito em 8 de fevereiro de 2021.

\begin{abstract}
Neste artigo, é apresentada uma visão geral sobre a pesquisa, o desenvolvimento e implementação de Sequências de Ensino e Aprendizagem (SEA) orientadas para tópicos de Ciências, além de sua validação em sala de aula. Como a literatura do tema é extensa, a escolha foi discutir fundamentos teóricos e ferramentas metodológicas para construir essas sequências e apresentar algumas propostas que foram, de fato, implementadas em salas de aula e que obtiveram bons resultados. De início, a metodologia de pesquisa chamada Aprendizagem Baseada em Design é analisada e sugerida como uma metodologia eficiente que abrange tanto o processo de design como a análise dos resultados de aprendizagem. Em relação às SEA, são discutidos os modelos Demanda de Aprendizagem, Reconstrução Educacional, modelo de "Dois-Mundos", Engenharia Didática e as Unidades de Ensino Potencialmente Significativas. Exemplos ilustrativos da aplicação e avaliação de SEA baseadas nesses modelos em vários contextos são apresentados. O objetivo principal do artigo é contribuir para que, com o aprofundamento das questões aqui colocadas, professores possam elaborar SEA teoricamente fundamentadas e didaticamente consistentes, com implementação factível no contexto real de sala de aula.
\end{abstract}

Palavras-chave: Sequências de Ensino e Aprendizagem, Aprendizagem Baseada em Design, Ensino de Física.

In this article, an overview of the research, development and implementation of Teaching and Learning Sequences (TLS) oriented to Science topics is presented, in addition to their validation in the classroom. As the literature on the topic is extensive, the choice was to discuss theoretical foundations and methodological tools to build these sequences and to present some proposals that were, in fact, implemented in classrooms and that obtained good results. Initially, the research methodology called Design-Based Research is analyzed and suggested as an efficient methodology that encompasses both the design process and the analysis of learning results. In relation to TLS, the Learning Demand, Educational Reconstruction, "Two-Worlds" model, Didactic Engineering and Potentially Significant Teaching Units are discussed. Illustrative examples of the application and evaluation of TLS based on these models in various contexts are presented. The main objective of the article is to contribute so that, with the deepening of the questions raised here, teachers can develop TLS theoretically grounded and didactically consistent, with feasible implementation in the real classroom context.

Keywords: Teaching-Learning Sequences, Design-Based Research, Physics Teaching.

\section{Introdução}

Uma das motivações do presente artigo consiste na articulação entre o conteúdo a ser ensinado e os conhecimentos utilizados pelos docentes na elaboração de Sequências de Ensino e Aprendizagem (doravante SEA). Dessa forma, pretende-se, por meio de um aprofundamento teórico, compreender o design pedagógico inerente a essa prática, apresentando os arcabouços teóricometodológicos envolvidos nesse processo, na tentativa de contribuir com o trabalho de professores, quando do desenvolvimento de tais sequências.

\footnotetext{
*Endereço de correspondência: lucasamesquita@hotmail.com
}

Desse modo, volta-se à técnica profissional do docente, sendo o termo "técnica" aqui utilizado não de forma pejorativa, reducionista, como se fosse um mero conjunto de regras a serem seguidas de maneira mecânica e sem reflexão. Pelo contrário, técnica será empregada neste texto como ato de produção, "qualidade de um ato consciente, imanente ao ser humano e acontecendo pela necessidade de produzir a sua existência, ou seja, pela realidade do homem no mundo" [1, p. 154]. Nesse sentido, essa acepção de técnica exige a compreensão profunda dos pressupostos teóricos que a orienta, referindo-se, portanto, ao ato de produção, de criação, teoricamente fundamentado e não à mera execução de um conjunto de procedimentos. 
Inicialmente, é preciso destacar diferenças encontradas na literatura entre as Sequências Didáticas (SD) e as Sequências de Ensino e Aprendizagem (SEA). Ainda que, inúmeras vezes, ambos os termos sejam tratados como sinônimos, tanto na prática da sala de aula, como em diversos referenciais teóricos, nas últimas décadas, surgiram proposições de caracterizações distintas criadas por pesquisadores especializados no estudo do tema. De modo geral, as SD estão mais fortemente relacionadas ao planejamento de ensino e à intervenção pedagógica, de modo a ser compreendida de maneira complexa, distinguindo-a de uma mera sequência de aulas ou da simples execução de tarefas educativas. Segundo Zabala [2], uma SD é o "conjunto de atividades ordenadas, estruturadas e articuladas para a realização de certos objetivos educacionais que tem um princípio e um fim conhecidos tanto pelo professor como pelos alunos". Assim, é possível perceber que as SD podem ser caracterizadas e investigadas de diferentes formas [3].

Quanto às SEA, esse artigo adota a concepção de Méheut e Psillos 4, que as definem como uma atividade de pesquisa do professor, essencial para sua prática docente, uma vez que ele as reformula sempre com base nos resultados obtidos previamente. Os autores assim as definem:

Uma SEA é uma atividade de pesquisa
interventiva e um produto, como um pa-
cote tradicional de uma unidade curricular,
que inclui atividades de ensino-aprendizagem
bem pesquisadas e empiricamente adaptadas
ao raciocínio do aluno. Às vezes, são também
incluídas diretrizes de ensino cobrindo as
reações esperadas dos alunos [4, p. 516].

Necessariamente, nesse processo, o professor investiga a sua própria prática. Esse é um aspecto bastante relevante das SEA, em comparação com as SD, usualmente construídas com base na definição de Zabala. Segundo os autores, as SEA têm características fundamentais:

denotam estreita ligação entre o ensino proposto e o aprendizado esperado dos alunos, como uma característica distintiva de uma sequência orientada por tópicos inspirados em pesquisa. [...] Elas são, ao mesmo tempo, atividades de pesquisa de intervenção e um produto, como um pacote de unidades curriculares tradicionais, que inclui atividades de ensino-aprendizagem bem pesquisadas, adaptadas empiricamente à compreensão do estudante. [4, p. 516].

Existe grande número de trabalhos que investigam o processo de construção das SEA, em geral, a partir de transposições didáticas do conteúdo científico, acompanhadas de guias de como implementá-las. Esses guias são baseados em fundamentos teórico-metodológicos e resultados de pesquisa empírica, bem como do conhecimento pedagógico desse conteúdo por parte dos proponentes da SEA.

Na seção 2, a metodologia de pesquisa baseada em design (DBR na sigla em inglês, e adotada a seguir) será apresentada como uma forma engenhosa de concepção, construção, implementação e análise de resultados das SEA. Na seção 3 procede-se a uma revisão bibliográfica seletiva, tratando diferentes abordagens teórico-metodológicas criadas especificamente para o desenvolvimento dessas sequências. A seção 4 trata da elaboração de sistema teórico-metodológico, proposto por Marco Antonio Moreira, que tem sido usado no Ensino de Ciências no Brasil e que se enquadra na estrutura das SEA: As Unidades de Ensino Potencialmente Significativas (UEPS). Na seção 5. alguns exemplos de construção das SEA baseados nos modelos teórico-didáticos discutidos nas seções anteriores são apresentados. A seção 6 traz as considerações finais dos autores.

\section{A Metodologia DBR (Design-Based Research)}

O Design-Based Research (DBR) busca refletir, de maneira mais ampla, como ocorre o aprendizado em situações complexas do contexto escolar e refina teorias de ensino para que, assim, se consiga obter modelos inovadores que, de fato, sejam eficientes em sala de aula [5]. Dessa maneira, é possível determinar "métodos que documentam os processos de implementação e fornecem evidências críticas para estabelecer garantias para reivindicações sobre o porquê dos resultados ocorridos" [6, p. 7].

Tal abordagem busca trazer evidências sobre a eficácia da implementação de intervenções em sala de aula. Nesse sentido, os anseios da DBR na educação estão, necessariamente, ligados ao desenvolvimento de teorias contextualizadas de ensino e aprendizagem, à exploração das possibilidades de criação de ambientes inovadores, à construção de aglomerados de conhecimento em design e ao aumento da capacidade humana para a inovação [6] . Além disso, a DBR é desenvolvida

com foco no design e teste de intervenções, usando métodos mistos, envolvendo várias iterações, decorrente de parcerias entre pesquisadores e profissionais, produzindo princípios de design, diferentes da pesquisaação, e preocupados com um impacto na prática [7, pp. 97-98].

A princípio, a DBR pode ser considerada como uma metodologia utilizada para aprimorar o processo de design. Maciel, Passos e Arruda 8] propõem a DBR como estruturante metodológico para pesquisas em ensino. Seu uso apresenta várias inovações, entre elas, estruturas de atividades, instituições, currículos e sistemas de reaplicação 6]. Dessa forma, entende-se que no uso da 


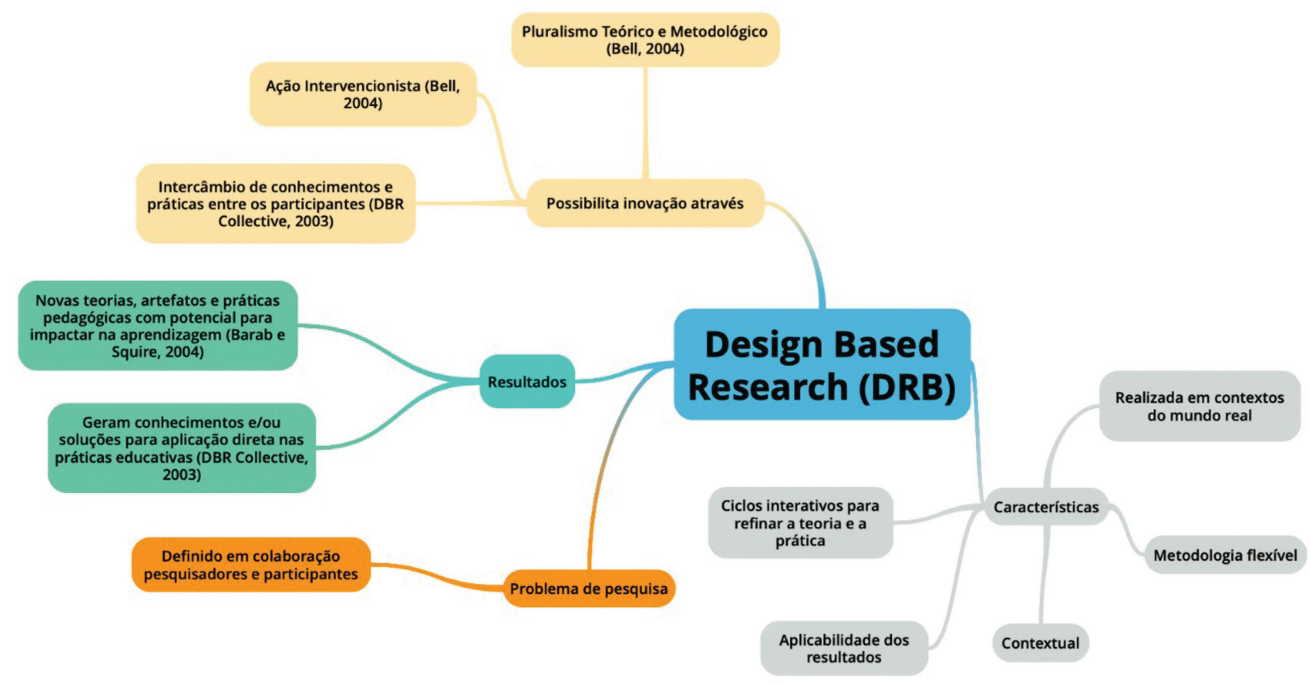

Figura 1: Diagrama conceitual sobre DBR, adaptado da Ref. [11] ${ }^{1}$

DBR não se deve somente ter como foco o processo, mas, mais do que isso, é preciso refletir sobre como as intervenções ocorrerão, quais teorias serão necessárias para fundamentar uma intervenção, qual o currículo vigente, quais as regulamentações e, principalmente, quais são os objetivos didático-pedagógicos e sociais do ensino de determinado conteúdo. Segundo Levin e O'Donnell 9], a DBR pode ser uma abordagem metodológica interessante e útil para gerar relatos de ensino e aprendizagem, servindo como suporte para diferentes análises mais profundas e específicas. Dessa forma, seu objetivo principal é, com estudos mais controlados, encontrar evidências que possam ajudar a caracterizar mecanismos, fatores contextuais e a natureza das intervenções. A DBR se diferencia de outras metodologias de pesquisa avaliativas, especificamente, em sua busca pela elucidação dos mecanismos existentes entre os caminhos contextuais e as intervenções.

Desse modo, na DBR, o pensamento global sobre o processo de design é vital na produção de uma SEA, pois, segundo Lijnse e Klaassen [10], a reflexão durante o design proporciona uma melhora na prática didática, possibilitando uma mudança guiada. Durante esse processo, deve-se decidir previamente o uso de abordagens e teorias mais apropriadas aos objetivos determinados para cada SEA. Os autores argumentam que essas decisões podem ser melhoradas na medida em que o designer domina e compreende os processos de ensinoaprendizagem, obrigando, assim, ao aprofundamento no entendimento de diferentes conhecimentos teóricos que orientam a prática.

Entre algumas características relevantes da DBR, apresentadas por Nobre et al. [11], podem ser destacadas para objetivos do presente texto:

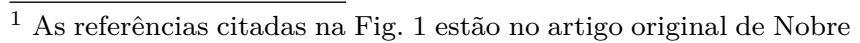
et al. 11.
}

- Metodologia flexível - que possibilita a evolução dos ciclos iterativos e o redesign constante;

- Baseada na teoria e prática e implementada em contextos do mundo real, de preferência, na sala de aula;

- Processo iterativo para ajustar a teoria e a prática;

- Aplicabilidade dos resultados - esses geram conhecimento e soluções para aplicações em práticas educacionais de modo a produzir mudanças significativas na aprendizagem dos alunos.

A Fig. 11apresenta um diagrama conceitual que aponta as principais características da DBR e suas conexões, de acordo com a Ref. 11 .

Kneubil e Pietrocola [12] propuseram um esquema que permite vislumbrar o processo de desenvolvimento da DBR, como mostrado na Fig. 2, Nele os autores sintetizam os fluxos e a ideia de reaplicação. Ademais, pode-se enxergar o potencial de desenvolvimento de objetos pedagógicos seguindo essa metodologia.

Como se percebe na Fig. 2 o processo inicia-se a partir dos princípios de design, que possuem alguns aspectos semelhantes com o que, a seguir, será destacado como instruções de design de Leach, Ametller e P. Scott [13]. Entretanto, para Kneubil e Pietrocola [12, eles são os arcabouços teóricos que irão estruturar o processo e as intervenções. É importante frisar que, segundo os autores, essas teorias devem se conectar com situações reais, assim, alinhando teoria e prática. Ademais, esses arcabouços não são fixos ou únicos, podendo ser constituídos a partir de vários aspectos de teorias de base, epistemologicamente coerentes, e variar com relação ao conhecimento ou situação em que a intervenção ocorrerá.

Aliado a isso, por meio do uso dos trabalhos de Kneubil e Pietrocola [12] e McKenney e Reeves [7], Maciel, Passos e Arruda [8] apontam uma série de parâmetros importantes da DBR, pautados a partir da natureza desse tipo de metodologia. Primeiramente, 


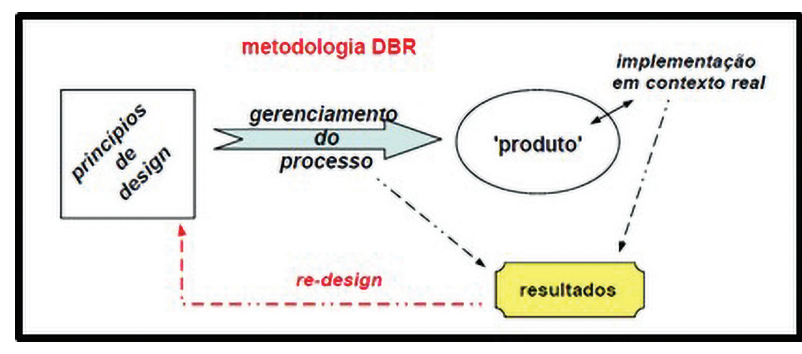

Figura 2: Esquema de design para DBR [12, p. 3].

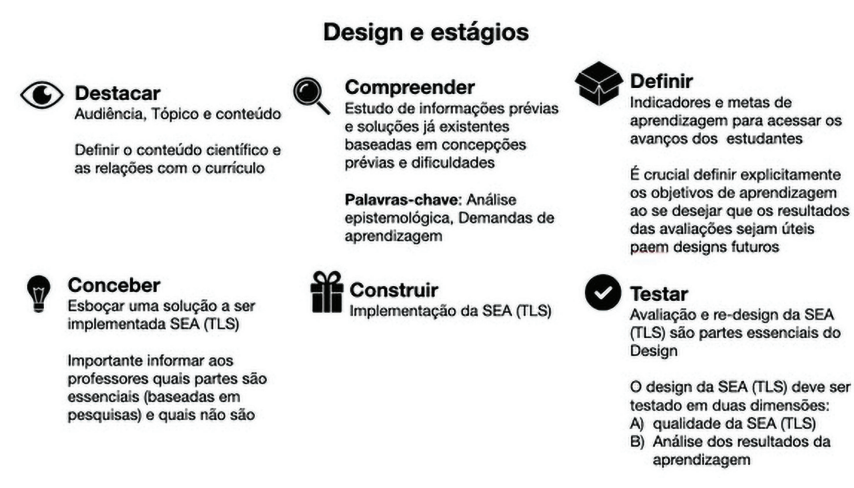

Figura 3: Passos a serem seguidos na implementação da metodologia DBR [14].

segundo os autores, as pesquisas em educação, como será enfatizado no escopo desse texto, devem ser teoricamente norteadas. Com isso, as ações no ensino necessitam partir de estruturas e aportes teóricos bem determinados.

Uma descrição mais detalhada do procedimento de implementação de fases da metodologia DBR foi dada por Guisasola et al. [14]. A Fig. 33 apresenta os vários estágios a serem cumpridos no design e avaliação de sequências de ensino e aprendizagem.

Guisasola et al. apresentam seis estágios para concepção, implementação e avaliação da metodologia DBR:

- Destacar: os designers estabelecem o público-alvo, objetivos, e o conteúdo a ser ensinado em relação ao currículo;

- Compreender: os designers analisam as possíveis dificuldades de compreensão do tópico por parte dos alunos e buscam-se, por exemplo, informações na literatura acerca das concepções prévias dos alunos. Os autores salientam que se trata de fase essencial no processo de elaboração, pois deve-se proceder a uma "análise epistemológica" do conteúdo e, em seguida, considerar as demandas de aprendizagem, isto é, analisar as diferenças epistêmicas e ontológicas entre os conhecimentos prévios dos alunos e o conteúdo científico a ser ensinado;

- Definir: Nessa fase, com base nos resultados da fase anterior, definem-se as metas de aprendizagem e os indicadores de avaliação;

- Conceber: Os designers elaboram um esboço do projeto que inclui os materiais a serem disponibilizados. Os autores julgam importante a discussão sobre a natureza da ciência se sua relevância para a sociedade. Sugerem atividades e problemas relacionados com a ciência, tecnologia, sociedade, e programas ambientais;

- Construir: essa é a fase de implementação do projeto;

- Testar: nesse estágio, avalia-se a eficiência do produto projetado.

Uma característica importante da metodologia DBR é o foco nos resultados e objetivos. Necessariamente, os pesquisadores devem realizar uma intervenção com intuito de transformar uma situação ou panorama educacional. Assim "a pesquisa em design educacional começa com a identificação de problemas educacionais significativos, que necessitam de soluções inovadoras e apropriados para investigação científica" [7] p. 8; 8, p. 554]. Além disso, tais resultados devem produzir produtos capazes de serem reaplicados em outros tipos de contextos, chamados de nichos.

É preciso também ressaltar outras duas características da DBR: a necessidade de replicação e os processos de redesign que compõem os ciclos de design. Dessa forma, a "análise sobre o processo e sobre a implementação deve gerar conhecimentos que serão usados num design posterior" [12, p. 4; 8, p. 554]. Além disso, McKenney e Reeves [7] apontam que uma das grandes características da DBR no ensino é o fato desse processo ser construído de forma colaborativa, entre grupos de trabalhos, formados por professores, pesquisadores e comunidade escolar. Tal fato faz a DBR se diferenciar de outras metodologias [15, 16. Na visão de Anderson e Shattuck [15], a DBR, além de lidar com situações reais de ensino e buscar intervenções que possam mudar a realidade da sala de aula, possibilita a utilização de uma gama de metodologias e coletas de dados. Os autores também destacam a maneira como as interações acontecem. Segundo eles, o fato de existirem várias interações na DBR permite que os protótipos e objetos de ensino sofram constantes mudanças. Assim, os grupos de pesquisa devem sempre procurar aprimorá-los, para que possam se adequar a diferentes nichos. Por conseguinte, essas mudanças levam a outra característica, a mudança dos princípios de design. Esse processo de evolução dos princípios, após as intervenções e nos ciclos de redesign é " [...] um dos pontos fortes da DBR, e isso desfavorece certos tipos de pesquisa que unilateralmente levam intervenções às salas de aula e desaparecem [... após a conclusão do experimento" [15, p. 17].

Não obstante, Bakker e Van Eerde [16] apontam que a DBR traz a generalização dos resultados ou métodos utilizados à sua transferibilidade. De acordo com essa visão, uma DBR com um conteúdo específico não deve apresentar respostas, por exemplo, para todo ensino de física, porém, necessita demonstrar aspectos que podem ser aplicados em outros nichos ou países. 
Entretanto, a DBR tem suas limitações. Sua aplicação efetiva requer a necessidade de redesign após aplicações e análise dos dados, assim como o envolvimento de outros pesquisadores e participantes. Outro possível complicador no uso da DBR é a dependência de uma situação controlada. Isso porque, em uma intervenção, há muitas interações, que requerem diferentes decisões dos indivíduos responsáveis pelo design (professores, designers e pesquisadores). Além disso, a manutenção dos indivíduos nos grupos de trabalho é imprescindível e a interação entre eles está intimamente ligada ao sucesso e validação dos dados. Tais dificuldades podem explicar o porquê do incipiente uso da DBR por parte dos pesquisadores brasileiros no ensino de ciências. Tal fato é constatado na escassez de referências nacionais. Nesse sentido, Tamiosso e Pigatto [17] analisaram 5 teses e dissertações e 7 artigos que utilizavam a DBR (ou como as autoras colocam, PDB - Pesquisa Baseada em Desenho) em pesquisas no idioma português e de acesso gratuito ao texto completo. Elas concluem que "[...] em geral, ainda são poucas as pesquisas que abordam a PBD no ensino de Ciências da Natureza. [...]" [17, p. 169]. Pesquisas de longa duração, com a participação de diversos pesquisadores e professores, com parceria com escolas e necessidade de aplicação, avaliação e reaplicação em contextos reais de sala de aula requerem, necessariamente, altos financiamentos e grupos de pesquisa já bem estabelecidos. Tais fatores devem contribuir sobremaneira para o pouco uso da DBR no país.

Por fim, a DBR pode ser compreendida como uma metodologia de pesquisa capaz de sofisticar e melhorar processos de ensino-aprendizagem, pois, por meio dos seus ciclos de redesign e reaplicação, ela permite que os pesquisadores aprimorem os objetos de ensino e as SEA, bem como suas atividades e material instrucional. Além disso, podem ser testadas em diferentes situações obtendo trabalhos cada vez mais robustos e aptos a serem aplicados em diferentes contextos escolares e situações de sala de aula. Com isso, a DBR surge para ajudar a detectar, por meio dos ciclos, aspectos e características do complexo universo do ensino, capazes de serem destacados e mantidos em futuras reaplicações.

\section{Aspectos e Estruturas das Sequências de Ensino e Aprendizagem (SEA)}

O arcabouço teórico-metodológico das SEA compila diversos aspectos do desenvolvimento de sequências de ensino e aprendizagem. Nesse caso, o olhar do designer vai além do conteúdo, mas analisa como esse conteúdo se relaciona com o cotidiano do aluno, com que tipo de abordagem o professor irá utilizar e como tudo isso se articula teoricamente, a fim de orientar, ao final, a prática pedagógica. Dessa forma, será mostrado que a SEA proporciona a evolução na criação de SEA, pois o professor, ao usá-la, necessita dominar e compreender uma série de aspectos que envolvem esse processo. Portanto, as SEA assumem um papel mais sofisticado, diferenciando-as bastante daquilo que, mais tradicionalmente, se considera como sequências didáticas. As SEA tornam-se instrumentos didáticos com objetivos educacionais bastante claros e teoricamente bem determinados e explicitados.

Inicialmente, deve ser destacado o artigo de Méheut e Psillos (2004) que consta da edição especial do International Journal of Science Education (IJSE), editado pelos próprios autores, e que oferecem uma visão ampla do estágio da arte das SEA até o ano de 2004. Esse artigo de Méheut e Psillos é em estudo seminal nesse campo constituindo a base teórica usada em inúmeros trabalhos subsequentes [12, 14, 18, 20].

Uma das primeiras contribuições trazidas refere-se à construção do losango didático, como ferramenta de análise das sequências criadas [4], conforme se observa na Fig. 4 .

Segundo os autores, quando uma SEA é criada, é preciso uma reflexão sobre alguns aspectos fundamentais, como situações e atividades de ensino-aprendizagem, as concepções e motivações do aluno, a análise do conteúdo, as teorias pedagógicas, possíveis restrições educacionais, dentre outras. A partir do losango acima, pode-se perceber que a SEA trabalha tanto como a ciência contempla o mundo do aluno, como a forma com que o professor se conecta com o discente.

A dimensão epistêmica (eixo vertical) é a dimensão que corresponde ao conhecimento que se deseja abordar, trabalha o mundo material do aluno. Nessa dimensão, é possível entender como se dão os processos de elaboração e validação dos conhecimentos científicos, ou seja, as metodologias científicas.

Já no eixo horizontal, trabalha-se a dimensão pedagógica. Ela representa a ação do professor, pois aqui se trabalha a interação professor-aluno. No encontro dessas duas dimensões, próximo ao vértice "aluno", situa-se o foco do desenvolvedor da atividade, ou seja, trabalha-se com as habilidades e competências que se deseja que o aluno consiga desenvolver por meio da interação entre o

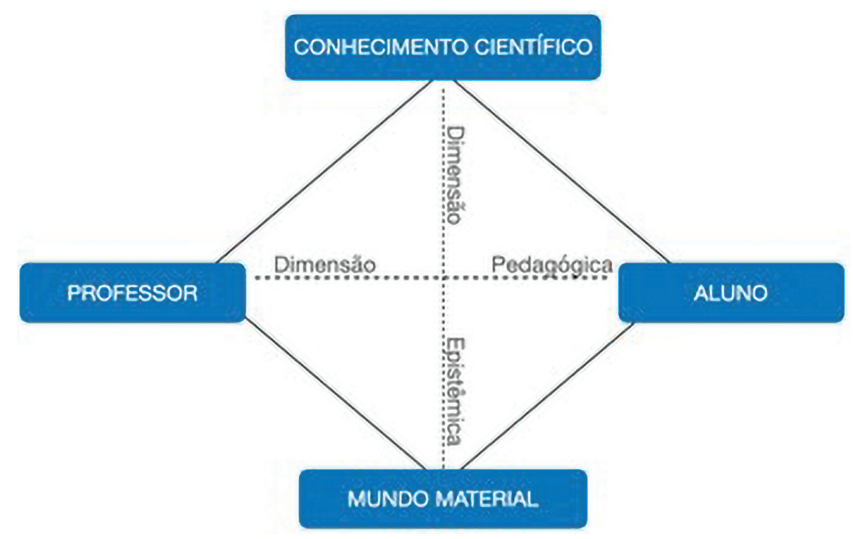

Figura 4: Losango Didático [4]. 
conhecimento científico, o mundo material e o professor. Dessa forma, tal ponto se encontra o resultado que o aluno obteve ao final do processo [4. Para a realização dessa análise, Méheut e Psillos usam o conceito de "construtivismo integrado". Para eles, esse conceito é uma fusão do conhecimento dos estudantes com as concepções do mundo que eles possuem, uma mescla entre a mudança das concepções prévias com a mudança de compreensão de fenômenos por meio de interações físicas.

A fim de revelar a importância desse processo, os autores se referem ao trabalho de Tiberghien e Barboux [21], que descreve uma aula sobre temperatura e calor. Eles chamam atenção para o esmero na confecção da aula, de tal modo que os alunos são levados a estabelecer uma conexão entre temperatura e equilíbrio térmico do sistema. Além disso, os autores ressaltam que, por mais simples que possa parecer o conhecimento a ser desenvolvido na aula, isso representa um grande salto para o aluno em relação às suas concepções anteriores. Ademais, destaca-se o trato com conceitos que dão novos significados a conceitos tradicionais dos alunos, como a temperatura.

Outra contribuição importante e que exerceu grande influência em trabalhos relacionados a SEA foi o de Buty, Tiberghien e Le Maréchal [22] que apareceu na edição especial do IJSE de 2004. Nele surge a proposta de uma grade como ferramenta que pode ajudar pesquisadores e professores a projetar e analisar uma SEA. Nas palavras dos autores [tradução nossa]:

A grade integra nossas hipóteses sobre o conhecimento e sobre o papel do conhecimento inicial dos alunos em relação à zona de desenvolvimento proximal. Ela permite que o designer análise e decomponha o conhecimento a ser ensinado e o conhecimento dos alunos, e compare-os e avalie-os. Isso ajuda a valorizar a noção da distância entre o conhecimento a ser ensinado e o conhecimento dos alunos. Com base nessa grade, essa comparação é feita de acordo com duas dimensões da análise do conhecimento: o conhecimento cotidiano e o conhecimento científico, por um lado, e os níveis de modelagem, por outro 22 p. 587].

Em cada célula da grade, mostrada na Tabela 1. são indicados os tipos de conhecimentos da sequência. Na coluna, cada tipo é classificado de acordo com os níveis de modelagem: o nível de ideias ou o nível do mundo material, ou a relação entre esses dois níveis. Na linha, os tipos de conhecimento são classificados de acordo com os processos de aprendizagem relacionados ao conhecimento prévio, vindo de instrução anterior ou da experiência cotidiana, ou também durante a SEA. Esse modelo ficou conhecido como o modelo de "dois-mundos".
Tabela 1: Ferramenta para o design de uma SEA no modelo de "dois-mundos" - a grade [22].

\begin{tabular}{lccc}
\hline & $\begin{array}{l}\text { Conhecimento } \\
\text { já adquirido } \\
\text { segundo o } \\
\text { currículo }\end{array}$ & $\begin{array}{l}\text { Conhecimento } \\
\text { conhecido a } \\
\text { partir da vida } \\
\text { cotidiana }\end{array}$ & $\begin{array}{l}\text { A ser } \\
\text { construído } \\
\text { (Física) }\end{array}$ \\
\hline $\begin{array}{l}\text { Mundo } \\
\text { teórico/ } \\
\text { modelo }\end{array}$ & $*$ & $*$ & $*$ \\
$\begin{array}{l}\text { Relação entre } \\
\text { teoria/modelo } \\
\text { e objetos/ } \\
\text { eventos }\end{array}$ & $*$ & $*$ & $*$ \\
$\begin{array}{l}\text { Mundo dos } \\
\text { objetos/ } \\
\text { eventos }\end{array}$ & & & \\
*Tipo de conhecimento envolvido em uma sequência ou \\
uma tarefa
\end{tabular}

Tiberghien, Buty e Le Maréchal [18] ampliam a discussão das ideias da proposta inicial dos autores publicada na Edição Especial. Aqui, os autores criam escalas temporais que ajudam a determinar o tempo de planejamento e de execução de uma atividade. Tais escalas permitem a diferenciação do papel individual de cada componente do ambiente escolar e suas responsabilidades nessas dimensões temporais. Dessa forma, tanto a aula, quanto a SEA, possuem as maiores durações, e essas são limitadas pelo sistema de ensino. Entretanto, ações que duram menos tempo são de encargos dos alunos e professores. Os docentes são responsáveis pelas tarefas, sejam elas em um laboratório ou a realização de um exercício. Caso, para realizar a tarefa, haja a necessidade de algo ser mudado no ambiente da sala ou na disposição dos alunos (distribuídos em grupos ou individualmente), ou se a atividade exige muitos questionamentos, entra-se na próxima parte da escala: a ambientação (phase no original). Com isso, os estudantes podem ocupar duas posições na escala temporal: a ativa e a cognitiva. A primeira refere-se à realização dos momentos propostos na atividade de maneira autônoma pelos alunos. Já a segunda, está relacionada ao desenvolvimento dos processos cognitivos dos estudantes. É importante frisar que elas não possuem relação de causa e efeito, ou seja, não significam obrigatoriamente que haverá aquisição de conteúdos ao final do processo [18.

Ainda segundo os autores, a diferenciação entre ensino e aprendizagem não se limita a essa análise temporal. Ela pode ser mais profunda, levando em consideração as teorias de aprendizagem que visam a relação do aluno e seu ambiente, ou os quadros teóricos que discutem o professor e sua prática. É ressaltado aqui a importância em se conhecer e explicitar as hipóteses iniciais sobre o conhecimento a ser ensinado, ou seja, revisar e estipular os parâmetros pedagógicos, cognitivos, conhecimentos didáticos, história, filosofia e epistemologia das ciências 
e legislações de ensino (currículo escolar, estadual ou nacional). Portanto, a modelagem das SEA é um processo bastante complexo, nos quais teorias do conhecimento (epistemológicas, cognitivas, pedagógicas etc.) devem estar imbricadas com o conteúdo científico e com os objetos tratados nas atividades que as compõem.

Dentro do processo inicial de sistematização das pesquisas em ensino, acredita-se que sejam válidas essas ações de categorizações, representadas pelos passos a serem dados na construção de uma SEA. Assim, segundo Leach, Ametller e Scott [13, tais passos devem estar presentes nas instruções de design e esses podem auxiliar a compreensão geral de todo o desenvolvimento, além de evidenciar os porquês das ações que foram tomadas nesse processo. Segundo os autores, as instruções de design não são meras compilações das condições sob as quais são aplicadas as sequências, mas as instruções possuem uma série de características específicas que possibilitam a compreensão, por parte de outros docentes e pesquisadores, dos processos e das decisões tomadas durante o design e a aplicação.

Em síntese, devem ser destacadas algumas dessas características. Como já foi dito, essas instruções não se limitam a uma descrição dos ambientes de aplicação da SEA. Todavia, a caracterização do contexto educacional é de suma importância, constituindo a primeira parte das instruções de design. Dessa forma, os aspectos e informações ligados ao currículo, aos alunos, ao professor, bem como às restrições institucionais e ao calendário acadêmico devem ser os primeiros pontos a serem descritos nas instruções. Com isso, caracterizam-se os nichos de trabalho, os limites impostos pela realidade, as legislações que orientam o trabalho docente e os recursos disponíveis.

As instruções de design devem conter os objetivos que se desejam alcançar e o conteúdo a ser trabalhado. Assim, Leach, Ametller e Scott 13 apontam que a descrição das mudanças e influências desejadas com a aplicação da SEA é extremamente importante para que se entenda os motivos de ações e atitudes tomadas durante todo processo. Ademais, os autores destacam que essa caracterização deve ser clara, cuidadosamente pensada, e precisa fazer parte do processo de design. Tal fato aponta uma perspectiva de estruturação da SEA na qual os objetivos didáticos-pedagógicos são resultados de ações conscientes e claramente descritas, alterando assim visões ingênuas ou artesanais sobre o processo de ensino, ou mesmo concepções baseadas em voluntarismos ou impressões pessoais. Por fim, as instruções de design devem conter a estrutura de trabalho, ou seja, deve-se, enquanto designer, demonstrar as estratégias pedagógicas e a sequência do conteúdo. Novamente, os autores apontam a necessidade de uma descrição com um grande nível de detalhament ${ }^{2}$ para que todos

\footnotetext{
2 Leach, Ametller e Scott [13] apresentam o termo "Grain Size", traduzido aqui como nível de detalhamento. Essa expressão
}

os processos e estratégias possam ser compreendidos por outros pesquisadores e docentes. Além disso, essas ações devem ser estruturadas e embasadas em teorias educacionais, cognitivas e filosóficas. Nesse sentido há aproximação e semelhança com a chamada demanda de aprendizagem.

A Demanda de Aprendizagem (The Learning Demand), proposta por Leach e Scott [23, ressalta que a criação de SEA deve, necessariamente, contemplar as concepções prévias dos alunos, juntamente com os conceitos e o discurso científico. A ideia é tratar a aprendizagem de ciências a partir da valorização dessas concepções e, principalmente, das compreensões de mundo que delas emergem [24]. Com isso, o professor é um agente que desempenha um papel de destaque na iniciação aos conteúdos científicos para o entendimento do universo. Dessa forma, foca-se no conhecimento a ser trabalhado visando entender quais são os processos necessários para se considerar as duas "linguagens" envolvidas na aprendizagem dos conteúdos científicos: a social, presente nas concepções prévias dos alunos, e a da ciência, que ainda precisa ser aprendida. Segundo os autores, o designer deve analisar como essas linguagens se diferem e, principalmente, como trabalhar os conceitos a serem estudados a partir dessa diferença. Nessa análise, deve-se identificar as naturezas dessas demandas de aprendizagem e os padrões de raciocínio nos quais as explicações criadas pelos estudantes são baseadas. Com isso, o professor necessita compreender as três naturezas da demanda de aprendizagem: a conceitual, a ontológica e a epistemológica. Aqui, entende-se a primeira como o processo de caracterização e descrição de um fenômeno com o conhecimento prévio dos alunos, como quando eles empregam "[...] noções cotidianas (por exemplo, "movimento implica força") ao invés de conceitos científicos ("aceleração implica força líquida")" [24, p. 81].

Já a dimensão ontológica da demanda de aprendizagem refere-se à compreensão da natureza de um ente. Dessa forma, os alunos possuem uma compreensão cotidiana da constituição de um corpo, em contraponto à compreensão científica de um fenômeno perceptível em tal corpo. Sendo assim, como exemplo, para o aluno, o "[...] "ar não é nada", em oposição a "pressão do ar é uma força" [...]" [25, p. 636], apontando-se, assim, uma demanda de aprendizagem ontológica.

Por fim, há a natureza epistemológica da demanda de aprendizagem, segundo os autores, uma das mais presentes na sala de aula. A natureza epistemológica diz respeito à necessidade de se conseguir reaplicar os conteúdos aprendidos em situações diversas das quais eles foram ensinados. Assim, há uma grande dificuldade nesse processo, pois os alunos ainda são muito dependentes do contexto que em um conceito foi apresentado,

descreve o esmero de um processo de criação de sequências, ou como os autores expõem: "usamos o termo "Grain Size" (Nível de detalhamento) para descrever o nível de detalhe no qual um processo ou prática é descrito" (p. 8). 
sem serem capazes de extrapolarem seu uso para outros contextos.

Indubitavelmente, o processo de desenvolvimento das pesquisas em SEA é vasto e não é possível, e nem há a pretensão de resumir nesse texto todas suas vertentes e linhas de pesquisa. Todavia, entende-se a necessidade de que algumas outras propostas de pesquisa bastante relevantes para o Ensino de Física sejam abordadas.

Outro importante modelo para elaboração das SEA é a reconstrução educacional, que decorre dos trabalhos de Reinders Duit e colaboradores a partir de $1996[26,27]^{3}$

A partir de Kattman et al. 26, entende-se a reconstrução educacional como uma abordagem construtivista na qual a linguagem científica e as concepções de mundo dos alunos são igualmente importantes para construção do aprendizado. Além disso, essa abordagem parte da concepção que não há uma estruturação única e verdadeira do conteúdo científico, pois o que se acredita como verdade, na estrutura do conceito científico, é apenas um consenso de um grupo de cientistas da área do conhecimento em que esse conteúdo está alocado. Ademais, Kattman et al. 26] destacam que a utilização da reconstrução educacional no processo de design e desenvolvimento de atividades possui aspectos importantes que, resumidamente, são: a visão científica do conteúdo a ser ensinado (de maneira inicial para destaque dos principais pontos); a história e filosofia das ciências do conceito; conhecimentos prévios dos alunos em relação ao conceito ou fenômeno; as lacunas dos estudantes em relação à compreensão do conteúdo e às motivações e feedbacks dos participantes durante e ao final do processo.

Com influência na didática alemã, a reconstrução educacional estabelece uma conexão entre o conhecimento científico e as concepções de mundo dos alunos para que, juntas, formem uma revolução na forma de entender o universo. Assim, o professor deve tornar o conteúdo acessível, de modo que o estudante consiga entender as abstrações das ciências e, dessa forma, compreendêlas para "reconstruir" sua compreensão do mundo e de seus fenômenos [24]. Além disso, destaca-se que a visão reconstruída dos estudantes é "menos complexa" do que discurso científico, ao mesmo tempo, que tal visão compreende as principais características do conteúdo científico.

Outro referencial bastante utilizado no Brasil surge da chamada "Didática Francesa". A Engenharia Didática é originária da didática da matemática, com influências dos trabalhos de Chevallard e Brousseau. A proposição teórica de Michèle Artigue [28] apresenta uma metodologia de pesquisa na qual o professor, ao criar uma SEA, deve ter o pensamento semelhante ao de um engenheiro, ou seja, ele deverá utilizar conceitos científicos, teorizando o processo didático, tendo em mente

${ }^{3}$ A Ref. 27] se baseia em visões anteriores dos principais aspectos do modelo de reconstrução educacional. Para maior detalhamento do modelo, recomenda-se a leitura dos artigos com colaboradores, citados nesse capítulo de livro. ambientes mais complexos e objetos de estudo menos controlados que os objetos tratados pelas ciências exatas [29, 30]. Segundo Almouloud e Silva 30, o desenvolvimento da Engenharia Didática deve seguir parâmetros específicos: análises preliminares; concepções e análise $a$ priori das situações didáticas; experimentação; análise $a$ posteriori e validação.

Sendo assim, em um primeiro momento, o professor deve utilizar-se de teorias didáticas, de suas experiências de sala de aula, pesquisa atuais em ensino e até de concepções prévias dos alunos para o desenho inicial da SEA. Feito isso, parte-se para análise das situações didáticas, nas quais o professor irá delimitar possíveis variáveis e comportamentos dos processos de ensino e desenvolver o desenho de sua sequência. Por conseguinte, parte para aplicação da SEA, recolhendo dados e registros que podem, futuramente, contrastar, confirmar ou refutar hipóteses ou variáveis criadas antes da aplicação da sequência. Dessa forma, ao final da validação, o professor pode determinar quais resultados são oriundos de aspectos fixos da SEA e quais são frutos das variáveis do processo de ensino e do contexto de aplicação [29, 30].

\section{A Unidades de Ensino Potencialmente Significativas (UEPS)}

Nessa seção, destaque é dado a um referencial que tem sido utilizado no Ensino de Ciências no Brasil e que se enquadra na estrutura das SEA: As Unidades de Ensino Potencialmente Significativas (UEPS). As UEPS surgem no trabalho de Moreira [31], que tem como base principal de sua proposição teórico-metodológica a Teoria de Aprendizagem Significativa [32, 33] como princípio norteador para a elaboração de SEA.

Para Ausubel, o ser humano aprende mediante a interação entre uma nova informação e uma estrutura cognitiva já existente, sendo preciso, então, considerarse, sempre, as ideias prévias dos estudantes. Desse modo, nas UEPS, Moreira [31 aponta a necessidade dos novos conhecimentos se ancorarem nos conhecimentos que os alunos já possuem, esses últimos chamados de subsunçores, relacionando, por meio de pontes cognitivas, o novo com aquilo que o aprendiz ja' sabe. $\mathrm{Na}$ Teoria de Aprendizagem Significativa, reforça-se a necessidade de o processo de ensino ter sentido para o estudante, para que, significativamente, ele possa de fato aprender. Moreira 34] ressalta a importância do planejamento docente, haja vista caber ao professor propor intervenções didáticas que propiciem o surgimento de conflitos cognitivos, elemento essencial na contraposição entre esquemas antigos e novos conhecimentos, o que permite a construção de uma nova rede hierárquica de conceitos. Dessa forma, com elementos fundados nessas linhas de pensamento, destacamos alguns pontos de Moreira 31] em relação à criação das UEPS:

- o conhecimento prévio é a variável que mais influencia a aprendizagem significativa. Organizadores 


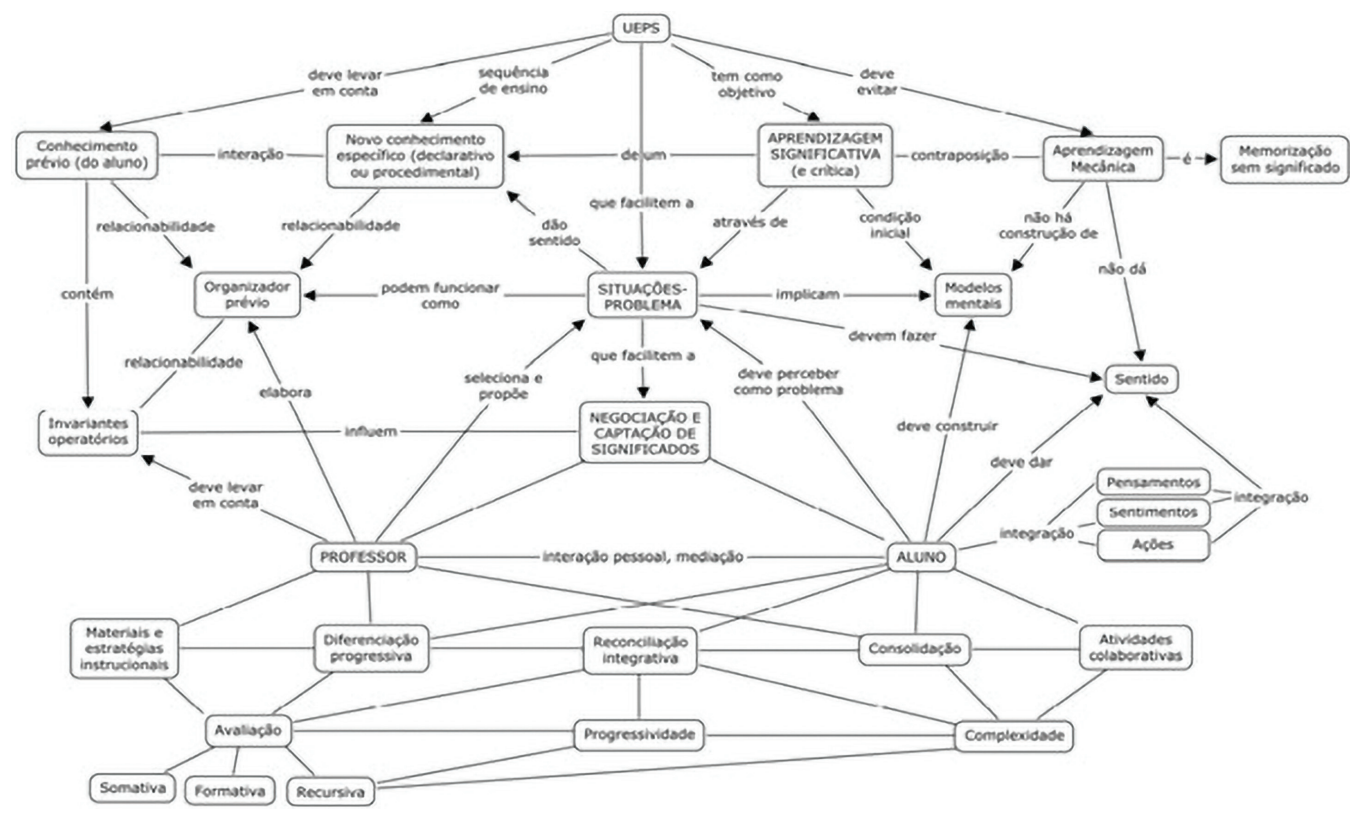

Figura 5: Mapa conceitual estrutural para construção de UEPS [31, p. 7].

prévios mostram a racionalidade entre novos conhecimentos e conhecimentos prévios;

- pensamentos, sentimentos e ações estão integrados no ser que aprende; essa integração é positiva, construtiva, quando a aprendizagem é significativa;

- são as situações-problema que dão sentido a novos conhecimentos; elas devem ser criadas para despertar a intencionalidade do aluno para a aprendizagem significativa e podem funcionar como organizadores prévios, devendo ser propostas em níveis crescentes de complexidade;

- a diferenciação progressiva, a reconciliação integradora e a consolidação devem ser levadas em conta na organização do ensino, tal como apresentado por Ausubel [30];

- a interação social, a linguagem e os materiais didáticos são fundamentais para a captação de significados, estimulando-se a busca de respostas, ao invés da memorização de respostas conhecidas.

Ao definir o aspecto sequencial de implantação das UEPS, o autor ressalta a importância de: (a) definirse o tópico a ser abordado, levando-se em consideração as vertentes conceituais e procedimentais; (b) propor situações-problema em níveis introdutórios e relacionadas com os conhecimentos prévios discentes, proporcionando a oportunidade desses elaborarem modelos mentais para solucionar a situação exposta, dando sentido ao surgimento de novos conhecimentos; (c) apresentar o conteúdo de forma a incentivar atividades colaborativas entre os estudantes; (d) retomar a explicação do conteúdo, inserindo relações estruturantes e mais complexas do tema abordado, trazendo relações de diferença e generalização em relação à situação-problema, promovendo a reconciliação integradora; (e) à guisa de conclusão, dar seguimento à diferenciação progressiva, inserindo novas situações-problema para que sejam solucionadas de forma colaborativa pelos alunos; (f) a avaliação deve ser, fundamentalmente, processual, com a observação de evidências de aprendizagem no decorrer do processo. Sugere-se, também, a aplicação de avaliação somativa individual, com a proposição de novas situações desafiadoras aos discentes.

Como síntese do processo de utilização das UEPS, Moreira 31] apresenta um mapa conceitual com as principais etapas envolvidas, mostrado na Fig. 5

\section{Alguns Exemplos}

Todas as pesquisas e referenciais discutidos nessa revisão corroboram para o desenvolvimento cada vez mais sofisticado de pesquisas acerca da construção de SEA teoricamente fundamentadas e capazes de serem modificadas e testadas em diferentes contextos educacionais. Dessa forma, alguns exemplos práticos da DBR e SEA são necessários, visando uma expansão de seu uso e desenvolvimento por professores e pesquisadores. Portanto, além das pesquisas já citadas nesse texto, é recomendável destacar, resumidamente, uma série de artigos que compilam a variabilidade do uso desses arcabouços teóricosmetodológicos e transparecem seus potenciais. Para tal, aspectos específicos, exemplos das abordagens já mencionadas ou possíveis parâmetros de desenvolvimento são apresentados a seguir.

Os exemplos citados nessa seção refletem propostas nacionais e internacionais e aqui são utilizados como fonte de inspiração para que professores e pesquisadores interessados nessa temática de pesquisa ou desenvolvimento de sequências de ensino possam aumentar seu 
repertório e favorecer potenciais articulações de suas práticas. Assim, como já inferido anteriormente no artigo, o desenvolvimento de SEA, principalmente no contexto brasileiro, se dá, em sua maioria, por professores universitários. Tal situação, infelizmente, é reflexo das condições gerais de trabalho dos docentes brasileiros, onde a rotina laboral é constituída de uma alta carga didática, restando pouco tempo para estudos e planejamentos de novas intervenções pedagógicas. Por isso, ao trazer tais exemplos de práticas de desenvolvimento de sequências didáticas, pretende-se focar, exatamente, nessa dificuldade do profissional brasileiro em dispor de tempo de jornada de trabalho além da sala de aula.

Inicialmente, ressalte-se o trabalho de Savinainen et al. 35, no qual se utiliza a demanda de aprendizagem para desenvolver uma SEA acerca de conceitos da terceira lei de Newton, introduzida como uma propriedade de uma interação. A escolha da abordagem inicial do conteúdo é crucial para a demanda de aprendizagem, haja vista que essa abordagem é fundamentada em mecanismos e vias de mudanças conceituais. Os autores apontam que, para o ensino desse conteúdo específico, aparentemente simples, a demanda de aprendizagem é bastante grande, pois há um longo caminho a ser percorrido para que se alcance a mudança conceitual desejada, retirando o aluno da relação com seu conhecimento espontâneo de mundo e permitindo a compreensão do discurso e da análise científica. Dessa forma, Savinainen et al. 35. esperam que os estudantes sofram mudanças nos aspectos ontológicos, conceituais e epistemológicos em relação ao conteúdo. Portanto, designers e pesquisadores devem proporcionar atividades que gerem subsídios para que os alunos consigam suprir essas demandas de aprendizagens. Para isso, os autores sugerem a elaboração de diagramas completos realçando as interações e destacando as forças e seus agentes causadores como no esquema mostrado na Fig. 6

Esse tipo de diagrama consegue trabalhar as demandas de aprendizagem necessárias nos três aspectos destacados. Assim, as características visuais e representações desse tipo de ferramenta podem levar o aluno a:

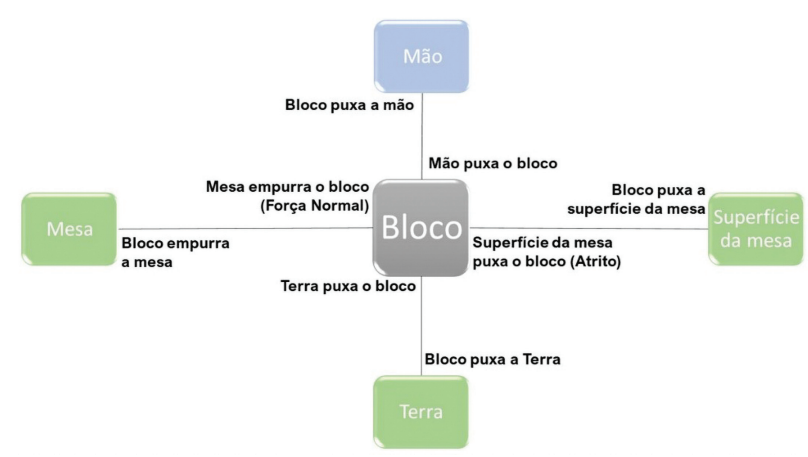

Figura 6: Diagrama explicitando as interações que surgem quando um bloco é empurrado com a mão em uma mesa [35 p. 122].
[...] perceber as forças como uma propriedade de uma interação ao invés de uma propriedade de um objeto (aspectos ontológicos). Em segundo lugar, uma interação simétrica entre dois objetos é explicitada anotando as interações (aspectos conceituais). Em terceiro lugar, a aplicação sistemática do diagrama de interações em várias situações ajuda os alunos a ver que a 3a lei é válida em todas as situações, independentemente das características contextuais (aspectos epistemológicos) [35, p. 122].

Outro exemplo emblemático do uso de demanda de aprendizagem encontra-se em Guisasola e colaboradores [14]. Nesse artigo, os autores propõem uma SEA para um curso introdutório de Física, focada nos conceitos de trabalho e energia. O desenvolvimento da sequência inicia-se na fase Destacar, com a definição do conteúdo curricular a ser trabalhado para, em seguida, continuar para a fase Compreender. Nesta etapa, são discutidas a epistemologia e a história (desenvolvimento, mudanças e evolução) do conteúdo, além do levantamento das concepções prévias dos estudantes. Após essa análise, inicia-se a fase Definir. Aqui, surgem os indicadores e as demandas de aprendizagem que irão modular as atividades e os caminhos que devem ser percorridos para que existam mudanças conceituais no decorrer da aplicação e desenvolvimento da SEA, como se pode avaliar no Quadro 1 .

$\mathrm{O}$ artigo salienta que os indicadores de aprendizagem são importantes instrumentos de validação da sequência.

Quadro 1: Indicadores de aprendizagem para definir o conceito de trabalho e as limitações do teorema da energia cinética [14 p. 6].

\begin{tabular}{|c|c|}
\hline $\begin{array}{l}\text { Elementos epistemológicos } \\
\text { da física }\end{array}$ & $\begin{array}{l}\text { Indicadores de } \\
\text { aprendizagem }\end{array}$ \\
\hline $\begin{array}{l}\text { Estabelecer os } \\
\text { elementos que farão } \\
\text { parte do sistema. Isso } \\
\text { torna possível definir as } \\
\text { forças externas sobre o } \\
\text { sistema e quais tipos de } \\
\text { energia mudam ou não } \\
\text { mudam. A definição do } \\
\text { problema leva à seleção } \\
\text { de estratégias para } \\
\text { resolvê-lo. } \\
\text { - Quantificando o } \\
\text { trabalho externo. } \\
\text { Em particular, } \\
\text { reconhecendo o trabalho } \\
\text { realizado pelas forças de } \\
\text { atrito como uma forma } \\
\text { de transferência de } \\
\text { energia }\end{array}$ & $\begin{array}{ll}\text { i.1. } & \text { Definir e aplicar esta } \\
\text { definição de trabalho } \\
\text { como um produto } \\
\text { escalar de duas } \\
\text { magnitudes. } \\
\text { i.2. } & \begin{array}{l}\text { Definir sistema e } \\
\text { compreender o }\end{array} \\
\text { trabalho como uma } \\
\text { transferência de } \\
\text { energia, o que implica } \\
\text { uma variação da } \\
\text { energia do sistema. } \\
\text { i.3. } \\
\text { Reconhecer que o } \\
\text { teorema da energia } \\
\text { cinética é um caso } \\
\text { particular do princípio } \\
\text { generalizado de } \\
\text { trabalho e energia. }\end{array}$ \\
\hline
\end{tabular}


Ademais, tais indicadores, junto com as demandas de aprendizagem, norteiam o designer, de modo que ele possa demonstrar a outros pesquisadores e docentes o que fundamenta cada etapa, além do sequenciamento e estrutura da SEA. Sob essa ótica, é importante salientar que os autores legitimam o uso do termo "indicador", ao invés de "objetivo". Eles defendem essa terminologia, porque quando o aluno atingir a capacidade descrita pelo indicador, isso poderá ser observado, tornando-se, então, um instrumento de validação da SEA. Com isso, o sucesso da sequência não está ligado somente a atingir objetivos, mas indicar e, principalmente, mensurar o desenvolvimento de habilidades e competências dos alunos. Sabendo que esse desenvolvimento não é imediato, necessitando um caminho a ser percorrido, a demanda de aprendizagem é utilizada como ferramenta de criação da SEA, pois permite ao designer projetar o que será necessário trabalhar para se atingir os indicadores propostos.

Com os indicadores e as dificuldades elencadas, como mostra o Quadro 2, o designer passa a criar atividades que permitam aos alunos desenvolverem as habilidades necessárias para compreenderem o conteúdo, suprindo os desafios e atingindo os indicadores estipulados. Guisasola et al. 14] criam uma série de problemas para que os alunos passem a entender o conteúdo de forma mais abrangente, além de desenvolverem as habilidades e competências previamente estipuladas. Assim, destacase no Quadro 3 o problema intencional, o indicador que se deseja alcançar com a habilidade trabalhada, a estratégia para tal e a atividade presente na sequência.

Os autores também propõem alguns procedimentos que buscam identificar necessidades de transformação da SEA, corroborando com um importante aspecto da DBR, o ciclo de redesign. Comumente vistos como uma ferramenta burocrática de registro de aula, na Ref. [14],
Quadro 2: Demandas de aprendizagem para os três indicadores de aprendizagem definidos na legenda do Quadro 1 [14, p. 6].

\begin{tabular}{lc}
\hline Dificuldades de Aprendizagem & $\begin{array}{c}\text { Indicadores } \\
\text { de aprendizagem }\end{array}$ \\
\hline $\begin{array}{l}\text { Dificuldades em definir trabalho externo } \\
\text { no princípio generalizado de energia são, }\end{array}$ & i.1; i.2 \\
parcialmente, devido a: & \\
- Dificuldades no produto escalar da & \\
$\quad$ definição de trabalho. & \\
$-\quad$ A falta de uma definição explícita do & \\
$\quad$ sistema que se aplica. & i.2 \\
Dificuldades em definir os tipos de & \\
energia do sistema. A definição dos tipos & \\
de energia depende do sistema & \\
selecionado. Por exemplo, as definições & \\
de energia potencial e trabalho externo. & i.2; i.3 \\
Interpretação incorreta da definição de \\
energia interna do sistema. Dificuldades \\
para distinguir trabalho externo e \\
trabalho realizado por forças dissipativas. \\
\hline
\end{tabular}

os diários de professores assumem a função de objeto de comunicação entre designers e implementadores. Nesses registros deverão conter informações acerca da implementação da SEA, além de comentários e apontamentos sobre pontos positivos ou possíveis dificuldades e erros na intervenção. Essa comunicação é essencial para DBR, metodologia de pesquisa que exige uma constante troca de informação entre o grupo. É proposto, então, um outro instrumento de avaliação: o relatório de avaliadores externos, feito por uma pessoa que pertença à equipe de design ou que seja participante da pesquisa. Esse instrumento visa identificar erros na implementação ou distorção dos objetivos por parte dos professores aplicadores da SEA. Além disso, os profissionais que

Quadro 3: Adaptação para apenas estratégias a e b. [14 p. 6].

\begin{tabular}{|c|c|c|c|}
\hline $\begin{array}{l}\text { A seção sobre "Como o t } \\
\text { da SEA sobre trabalho } n\end{array}$ & $\begin{array}{l}\text { no feito em ur } \\
\text { co e energia. }\end{array}$ & de partículas e a energia que é & sferida podem ser \\
\hline Problemas intencional & $\begin{array}{l}\text { Indicadores de } \\
\text { aprendizagem }\end{array}$ & $\begin{array}{l}\text { Estratégias para promover a } \\
\text { aprendizagem }\end{array}$ & $\begin{array}{l}\text { Atividades e comentários } \\
\text { Implementação e re-design }\end{array}$ \\
\hline $\begin{array}{l}\text { Como quantificar as } \\
\text { relações entre trabalho e } \\
\text { energia? }\end{array}$ & i. $2 ;$ i. 3 & $\begin{array}{l}\text { a. Familiarizando os alunos } \\
\text { com a análise dos fenômenos } \\
\text { que mostram as relações } \\
\text { entre trabalho e energia: }\end{array}$ & $\begin{array}{l}\text { Planilha para implementar as } \\
\text { estratégias a e b: }\end{array}$ \\
\hline & & - Definindo sistema. & $\begin{array}{l}\text { A.10 (movimento de mudança } \\
\text { W- } \Delta \mathrm{E}) ;\end{array}$ \\
\hline & & $\begin{aligned} \text { - } & \text { Diagramas de força. } \\
\text { - } & \text { Definição de trabalho } \\
& \text { externo e interno ao } \\
& \text { sistema. }\end{aligned}$ & $\begin{array}{l}\text { A.11 (variação elástica } \mathrm{W}-\Delta \mathrm{E}) \text {; } \\
\text { A.12 (energia interna } \mathrm{W}-\Delta \mathrm{E}) ;\end{array}$ \\
\hline & & $\begin{array}{l}\text { b. Organizar a informação } \\
\text { empírica e propor hipóteses } \\
\text { sobre a relação entre } \\
\text { trabalho e energia. }\end{array}$ & $\begin{array}{l}\text { A.13 (escolher um sistema e } \\
\text { relacioná-lo com } \mathrm{W} \text { e } \Delta \mathrm{E})\end{array}$ \\
\hline
\end{tabular}


serão avaliados não saberão qual aula e quando esse avaliador externo fará a avaliação.

Por fim, as fichas ou registros de trabalho dos alunos "são um recurso para fomentar a aprendizagem ativa nas salas de aula e podem ser usadas de diferentes maneiras" [14, p. 8]. Os autores apontam que essas fichas devem ser preenchidas em grupo, engajados em discutir e indagar sobre o conteúdo no decorrer da atividade. Destaca-se que os alunos devem ter em mente quais são os objetivos das atividades, pois assim poderão atingir os resultados esperados pelos designers antes da intervenção. Guisasola e colaboradores expõem que os resultados da avaliação das SEA são importantes, pois geram indícios de necessidades de alteração em estruturas, procedimentos ou abordagens, fazendo com que o designer tenha que redesenhar a sequência, mudando a ordem das atividades ou textos e fichas de atividades. Assim, "a análise dos resultados fornece aos designers um feedback sobre a validade do SEA e seus pressupostos teóricos" [14, p. 9].

Diante disso, destaca-se que as instruções de design não são uma sumarização do processo de desenvolvimento das SEA, mas um arcabouço metodológico, que visa permitir que os processos de ensino sejam compreendidos por outros profissionais, buscando replicabilidade e validação em outros ambientes de ensino. As instruções incluem análise do currículo e realidade escolar, estratégias pedagógicas, pesquisas prévias dos professores, além das tomadas de decisões e caminhos percorridos para atingir objetivos [36]. No intuito de exemplificar tal processo, destacamos duas SEA de Leach, Ametller e Scott [36] com resultados distintos.

Uma das SEA trabalha circuitos simples (eletricidade é gerada, passa por fios e é utilizada) e as referentes instruções de design tinham estratégias pedagógicas voltadas para o uso de analogias (substituir noções de eletricidade por carga e energia) [36]. Assim, a sequência se inicia com uma atividade em que os alunos deveriam prever o que aconteceria quando circuitos elétricos simples, porém com fios muito longos, fossem ligados. Como esperado, muitos afirmaram que deveria haver um certo "tempo de atraso" entre o momento de ligar o circuito e acender a luz 36. A surpresa de alguns alunos por não observarem esse "atraso" contribuiu para discussão acerca dos modelos explicativos dos alunos. Dessa forma, a partir de uma analogia, foi possível realizar a conexão entre os conceitos físicos e o experimento, sobressaindo a eficiência das instruções de design, pois todo esse desenvolvimento foi antecipado durante o design da sequência. A SEA obteve resultados satisfatórios devido às estratégias pedagógicas mais detalhadas nas instruções de design e os pontos de partida dos alunos, presumidos pelos autores, serem mais realistas [36].

A segunda SEA, Modelling Change, tinha como objetivo trabalhar conteúdos de estrutura e comportamento da matéria. Inicialmente, os autores identificaram limitações na maneira como o conteúdo era apresentado no currículo, levando-os a utilizarem exames nacionais para compreender quais aspectos eram exigidos e quais as evoluções e limitações do conteúdo em relação a diferentes níveis de ensino. Concluíram que os modelos exigidos compreendem boa parte dos problemas em relação à estrutura da matéria, porém são limitados para explicar aspectos das diferenças físicas entre os sólidos e líquidos, por exemplo [36. Portanto, um dos objetivos da sequência foi apresentar um modelo da matéria que fosse compatível com o currículo obrigatório, mas que pudesse sanar essas limitações sem extrapolar o nível de ensino e o tempo hábil.

Feito isso, os autores realizaram uma revisão bibliográfica prévia, delimitando as principais dificuldades dos alunos perante a temática. Por conseguinte, puderam estipular as estratégias pedagógicas, assim, criando as demandas de aprendizagem necessárias. É importante salientar que Leach, Ametller e Scott [36] apontam que as estratégias pedagógicas, descritas nas instruções de design, devem ser ações pensadas e necessárias para desenvolvimento da sequência. Por exemplo, o uso de uma estratégia que utiliza evidências empíricas deve ocorrer quando uma demanda de aprendizagem em relação à compreensão de um fenômeno é necessária [36.

Deve-se salientar que as instruções de design não são um mapa do tesouro para a aprendizagem completa. Pelo contrário, o nível de detalhamento almejado por Leach, Ametller e Scott 13 busca justamente identificar as ações cruciais para o sucesso na aplicação em um nicho, ou os pontos que necessitam de modificações em outras aplicações. Nesse sentido, essa SEA não obteve resultados esperados. Todavia, devido ao nível de detalhamento, os autores puderem elencar pontos que culminaram naqueles resultados. Em suma, segundo eles, parte dos professores aplicadores não atenderam às necessidades do design. Além disso, os pesquisadores levantaram falhas nas instruções de design, como a falta de atenção dos desenvolvedores com o ambiente de aplicação e pressupostos dos professores. Um aplicador em especial, modificou a estrutura da sequência, pois presava demais por atividades práticas e, assim, incluiuas com o fundamento de que não tinha o suficiente [36]. Tal fato corrobora com o que foi discutido sobre as estratégias serem selecionadas a partir de demandas identificadas e não por intuições individuais. Além disso, tal reflexão e validação auxiliam o processo de redesign proposto pela metodologia DBR e pode ser destacado na fala dos autores: "não defenderíamos o uso da sequência de ensino Modelling Change por outros professores sem uma modificação significativa" [36, p. 149].

O trabalho de Stavrou, Duit e Komorek [37. é um exemplo de como as sequências podem trabalhar conteúdo das ciências que não fazem parte do currículo tradicional. Eles utilizam-se da reconstrução educacional para desenvolverem uma SEA voltada para análise e discussão da relação do acaso e determinismo, em sistemas não lineares. Para isso, utilizam quatro experimentos: o 
Quadro 4: Os "obstáculos-objetivos" considerados na Ref. 38 p. 837.

\begin{tabular}{llll}
\hline Conceito & $\begin{array}{l}\text { Concepção } \\
\text { do estudante }\end{array}$ & \multicolumn{1}{c}{ Obstáculo } & \multicolumn{1}{c}{ Objetivo } \\
\hline Tempo & $\begin{array}{l}\text { A noção de } \\
\text { tempo é difícil de } \\
\text { definir }\end{array}$ & $\begin{array}{l}\text { Os alunos assumem que o conceito de tempo } \\
\text { de que trata a ciência é o mesmo a que nos } \\
\text { referimos diariamente. }\end{array}$ & $\begin{array}{l}\text { Analisar o conceito de tempo de } \\
\text { diferentes perspectivas: do ponto de } \\
\text { vista filosófico, científico e psicológico }\end{array}$ \\
$\begin{array}{ll}\text { Tempo é uma } \\
\text { unidade }\end{array}$ & $\begin{array}{l}\text { Quando os alunos se referem ao conceito de } \\
\text { tempo de um suposto ponto de vista científico, } \\
\text { cometem erros como confundir os termos }\end{array}$ & $\begin{array}{l}\text { Para apreciar a gama de } \\
\text { possibilidades de representar } \\
\text { graficamente a magnitude do tempo }\end{array}$ \\
& $\begin{array}{l}\text { magnitudes e unidades. Além disso, eles não } \\
\text { estabelecem relações entre esses conceitos e o }\end{array}$ & \\
& significado do processo de medição da & \\
magnitude do tempo & Identificar os conceitos envolvidos no \\
& & processo de medição do tempo \\
\hline
\end{tabular}

pêndulo esférico, o pêndulo caótico, células de Bénard e o dendrito. Apesar de pouco comum, a temática é bastante interessante e permite a realização dos processos necessários para a reconstrução educacional. Ou seja, um conhecimento prévio do mundo dos alunos, a inserção de uma nova língua e conhecimento, o entendimento dos pontos-chave, para que assim os estudantes, utilizandose de toda essas experiências, compilem as informações e reconstruam suas concepções sobre determinismo e relação com o acaso. Nesse trabalho, alunos com idade entre 16 a 17 anos passaram a apresentar explicações cientificamente corretas, percebendo as relações determinísticas com o acaso. Os autores concluem que depois "[...] de completar a sequência de experimentos, a maioria dos alunos foi capaz de construir explicações sólidas sobre o comportamento dos sistemas com base no acaso e nas leis determinísticas" 37, p. 421].

Um exemplo da versatilidade do uso das SEA é o trabalho de Arriassecq e Greca 38. Nele, é desenvolvida uma sequência voltada para a teoria da relatividade restrita (TRR) no Ensino Médio. Com influências da história e filosofia das ciências, as autoras fazem recortes e discussões abordando um ponto importantíssimo para uma SEA: o conteúdo. É apresentada uma discussão histórica e epistemológica da origem da TRR, seus impactos na arte, filosofia e nas próprias ciências. Aponta-se que objetos de ensino devem se utilizar das concepções prévias dos alunos para, a partir delas, o designer encadeie "obstáculos objetivos" a serem vencidos. Esses obstáculos não devem ser percebidos como algo pejorativo, implicando em uma trava para aluno, mas uma projeção real e capaz de ser transponível pelo estudante, de modo que ele perceba uma mudança conceitual e atinja os objetivos desejados. Não obstante, essa superação de obstáculos não é inerte e espontânea, mas deve ocorrer nas atividades e nas mediações dos professores. Assim, a SEA deve ser projetada para proporcionar aos alunos artifícios e momentos capazes de levá-los à tal mudança conceitual. Destaque-se uma parte do quadro proposto por Arriassecq e Greca [38, adaptado no Quadro 4 para que o leitor possa compreender o encadeamento das relações e desdobramentos dos conceitos, concepções dos estudantes, obstáculos e objetivos, necessários para construção da SEA.

Fazio et al. 39 desenvolveram uma SEA sobre o conceito de onda mecânica e seus meios de propagação, focando na articulação entre os fenômenos ondulatórios e as características corpusculares de tais meios. Baseados no modelo de reconstrução educacional e com o uso de diferentes ferramentas pedagógicas, como experimentação e vídeos, os autores realizam uma investigação qualitativa com 75 estudantes de Ensino Médio, focando nas representações físicas do fenômeno e nas estratégias cognitivas utilizadas para modificar os modelos mentais interpretativos dos alunos. Nesse artigo, buscou-se alicerçar a SEA em diversas teorias de aprendizagem ligadas à construção e antecipação de modelos cognitivos discentes.

Na pesquisa desenvolvida por Pessanha e Pietrocola [40, a inserção de tópicos relativos à Física Moderna no Ensino Médio é revisitada do ponto de vista do design, implementação e análise de intervenções didáticas, em um processo iterativo realizado juntamente com os docentes, amparado na DBR. Ao abordarem a temática sobre aceleradores de partículas em escolas brasileiras e espanholas, os autores desenvolvem a sequência baseados nos princípios de design: epistemológico (ao lembrar que a visualização de fenômenos atômicos ampara-se no uso de aparelhos), didático (ao tratar da importância da construção de modelos científicos pelos discentes) e psicocognitivo (ao considerar a necessária evolução de modelos mentais dos alunos quando da aprendizagem de novos conhecimentos). Como resultado, apontam para a possibilidade das SEA e DBR gerarem conhecimentos didáticos efetivos para o docente, proporcionando reflexões no tocante à importância no gerenciamento do tempo didático, assim como o cuidado necessário na escolha de imagens e metáforas, que podem reforçar concepções espontâneas sobre a estrutura atômica. 
Também com o objetivo de inserir elementos de Física Moderna e Contemporânea no Ensino Médio, Batista e Siqueira 20] buscam apresentar uma sequência didática sobre radioatividade, baseada nos princípios teóricometodológicos da DBR-SEA, enfatizando a pouca produção científica brasileira nessa área. Buscando trazer a proposta como uma possibilidade de responder como, quando e por que as inovações educacionais funcionam na prática. Assim, os autores trazem importantes aspectos a serem considerados, como as peculiaridades do contexto de aplicação, a necessidade de compartilhamento das experiências didáticas, a consideração das concepções prévias dos estudantes, além da necessidade de a sequência estar articulada com referenciais teóricos de suporte e possuir a possibilidade de redesign progressivos.

Ainda sobre Física Moderna, destaca-se o trabalho de Savall-Alemany et al. 41. Nesse artigo, tem-se a descrição detalhada da produção, implementação e avaliação de uma SEA para introduzir um modelo quântico de emissão e absorção de radiação. Criada a partir de diferentes pesquisas em ensino de física, a sequência foi implementada no último ano do ensino médio em duas escolas na Espanha. Os autores partem do resultado de uma pesquisa realizada em 15 países diferentes, que mostra os conteúdos que mais aparecem nos currículos de quântica no Ensino Médio, "níveis discretos de energia" e "interação entre luz e matéria". A partir do reconhecimento que esses conteúdos evidenciam os limites da física clássica e que propiciam o ensino do pensamento científico por meio da construção de modelos, foi criada uma SEA estruturada na resolução de problemas. Há um breve resumo desta abordagem pedagógica, que coloca o professor no lugar central de criação dos problemas e orientação dos estudantes na busca por soluções. Com riqueza de detalhes, os autores descrevem todas as fases de criação da SEA que, ao final, foi composta de 12 aulas de 55 minutos. Esperava-se que, ao final, os estudantes se apropriarem de um modelo quântico de emissão e absorção de radiação, baseado no modelo de Bohr e no conceito de fóton. Mais que isso, os autores esperavam que a SEA permitisse que os alunos fossem capazes de "identificar quais fenômenos podem ser explicados por esse modelo, sob quais condições ele foi estabelecido e quais são suas limitações: para dar resposta a outros problemas, como a posição ou o movimento de um elétron em átomo, esse modelo não é suficiente e modelos baseados no conceito de orbital atômico precisam ser usados" [41, p. 6].

Aqui, destaca-se não apenas a criação da SEA, mas a robustez da pesquisa que avalia seus impactos na aprendizagem dos estudantes. Para isso, 74 estudantes foram alocados em um grupo experimental, ao qual foi apresentado o conteúdo por meio da SEA, e outros 67 alunos em um grupo controle, com o conteúdo apresentado de maneira tradicional, pela leitura do livrotexto presente no currículo. Ambos os grupos estavam

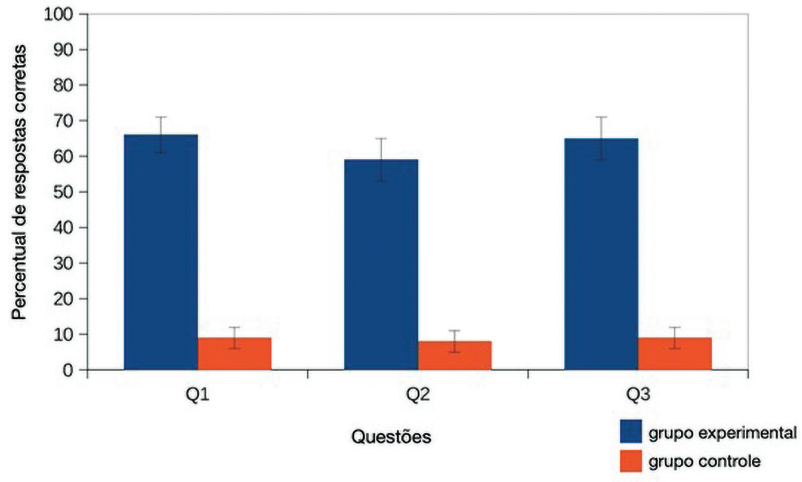

Figura 7: Percentual de acertos dos grupos experimental e controle nas questões do pós-teste [41 p. 6].

em escolas similares e tiveram o mesmo tempo de instrução dos fenômenos quânticos de emissão e absorção de radiação. Todos os alunos fizeram um pré-teste, validado por outros pesquisadores, e passaram por um pós-teste um mês depois do final do estudo. Além disso, dois dias depois do pós-teste, 5 estudantes do grupo experimental foram entrevistados. Como os estudantes não tinham conhecimento sobre emissão e absorção de radiação, nenhum deles, de ambos os grupos, acertou as questões do pré-teste, como esperado pelos pesquisadores. Contudo, no pós-teste, o grupo experimental apresentou um desempenho muito maior que o grupo controle. A Fig. 7 mostra os percentuais de acerto por questão.

Quando se considera todas as questões do pós-teste, $42 \%$ dos estudantes do grupo experimental acertaram todos os itens, enquanto nenhum estudante do grupo controle obteve o mesmo desempenho. Para investigar se os alunos realmente adquiriram o modelo quântico ensinado, ao invés de fornecerem respostas algorítmicas, os autores analisaram as falas de 5 estudantes em entrevistas estruturadas, bem como representações gráficas que fizeram para explicar a absorção e emissão de radiação. A análise das entrevistas é apresentada de forma detalhada no artigo, revelando que os estudantes, de fato, foram capazes de usar várias representações do átomo de forma coerente e cientificamente correta. Esse trabalho recente do grupo de Jenaro Guisasola 41 deve ser fonte central de referência para qualquer pesquisador interessado na produção/pesquisa de SEA.

Na linha de construção de UEPS, Pantoja e Moreira [42] buscaram o desenvolvimento de interações didáticas que pudessem abordar, de maneira significativa, o conceito físico de campo. Para tanto, basearam-se nos passos de aplicação da UEPS, além de se amparar nos Modelos Teóricos de Assimilação e Modelos Mentais. Tal arcabouço teórico demonstrou-se eficaz para identificar diversas interpretações do conceito de campo, construídas a partir de ideias alternativas dos estudantes e desenvolvidas em modelos mentais e esquemas gradualmente mais significativos. Desse modo, os autores 
constataram que a UEPS proposta facilitou o processo de condução à uma aprendizagem significativa, a partir da utilização de materiais e estratégias desenvolvidas intencionalmente para esse processo. Nesse sentido, Pantoja e Moreira também trazem a importância das UEPS no design curricular, destacando a facilidade que essa metodologia proporciona à organização de tópicos, seguindo os princípios de diferenciação progressiva, reconciliação integrativa, consolidação, organização sequencial, etc. Os autores sugerem, por exemplo, que se pode começar um curso de Física com discussões sobre a energia, transferências de momento e interações, ou pode-se dedicar uma UEPS para Ondas ou Eletromagnetismo e Mecânica Quântica, como tradicionalmente o tema é abordado. As UEPS permitem pensar em uma reforma curricular para o ensino de Física [42, p. 24].

A maioria das SEA, discutidas nessa seção, são dirigidas para a Educação Básica. Contudo há pesquisas para o ensino mais avançado da Física. Por exemplo, Bollen, Van Kampen e De Cock [43] apresentaram uma SEA voltada ao cálculo vetorial na eletrodinâmica. Nela, busca-se desenvolver habilidades para a compreensão das equações de Maxwell no formato diferencial, interpretação gráfica dos vetores espaciais, e cálculo de divergente e rotacional. A sequência inicia-se com o levantamento das possíveis dificuldades dos alunos a partir de resultados anteriores e pré-teste, ação essencial para o sucesso dessa SEA. Os autores elencam dificuldades, que perpassam desde operações vetoriais, representações de campos vetoriais, até habilidades nos cálculos de divergente e rotacional. Ao explicitarem tais dificuldades mostram como a SEA, mesmo quando proposta no Ensino Superior, é capaz de ser um instrumento eficaz para que o professor possa se adequar a diferentes ambientes de aplicação. No texto, é explicitado como pesquisas em ensino precisam possuir altos níveis de detalhamento para que possam transparecer necessidades e ações requeridas nas sequências. Tal fato é evidenciado quando os autores destacam que mais da metade dos alunos participantes do pré-teste possuíam habilidades em cálculos de divergente e rotacional. Devido a esse desempenho, não foi necessária nenhuma outra intervenção em relação a essa competência. Entretanto, esse não é um procedimento rígido, que engessa o processo de ensino, mas demonstra a futuros professores que, ao trabalharem com alunos que não possuam habilidades tão desenvolvidas, tomem atitudes diferentes em relação àquelas tomadas pelos autores.

Recentemente Pantoja e Moreira 44] construíram uma UEPS na busca de uma resposta à "Como se desenvolve a conceitualização, de estudantes de nível superior, do conceito de campo elétrico sobre eletrostática dando ênfase conceitual nas equações de Maxwell?" Foram aplicadas em dois grupos de estudantes, um deles de uma Universidade do Sul do Brasil (17 alunos) e o outro de uma Universidade do Norte do Brasil (11 alunos). Foram empregados os princípios filosóficos e aspectos sequenciais das UEPS de Moreira e para análise de dados a teoria dos campos conceituais de Vernaud [45]. A partir de uma análise detalhada dos resultados obtidos, a conclusão a que chegaram os autores é que, em geral, "houve evidência de construção de novos modos de conceitualização mais próximos dos científicos na maior parte das UEPS" [44, p. 13].

\section{Considerações Finais}

No presente artigo foi realizada uma revisão teóricobibliográfica, com vistas ao Ensino de Ciências, em particular da Física, acerca de metodologias específicas para a elaboração de Sequências de Ensino e Aprendizagem. A partir do aprofundamento teórico aqui exposto, uma questão crucial se apresenta: como elaborar uma SEA didaticamente consistente, com aplicação factível no contexto real de sala de aula e que promova uma aprendizagem significativa?

$\mathrm{Na}$ busca por uma resposta satisfatória, diversas pesquisas aqui apresentadas revelam evidências dos limites e, sobretudo, das potencialidades desses arcabouços teórico-metodológicos na melhoria do processo de ensino-aprendizagem no contexto de sala de aula. Tais metodologias têm gerado pesquisas robustas no Ensino da Física, com resultados prováveis de serem replicados em contextos mais amplos. Elas podem auxiliar o professor a compreender, de maneira mais profunda, a complexa ação de desenvolvimento de uma SEA. Além disso, elas buscam fornecer o uso de métodos e técnicas de design para estruturar e dar coesão a estas sequências. Para isso, exigem preparo, dedicação, estudo e reflexão, se distanciando da noção ingênua de um trabalho intuitivo, orientado apenas pela experiência docente, indo além da naturalização daquilo "que funciona ou não funciona" em sala de aula.

Após essa revisão, evidencia-se que a criação de uma SEA é um trabalho complexo e que possui diferentes referenciais teóricos próprios, que dão origem a metodologias específicas. Mesmo assim, deve-se entender que é impossível se desvincular dos vieses e valores pessoais e intuitivos. Porém, é imprescindível que se enfatize que tais valores podem ser atenuados, justamente a partir de pesquisas mais sólidas. As SEA não devem ter sua eficácia ligada aos valores particulares dos desenvolvedores, para que, assim, possam ser reaplicadas em outros nichos e contextos escolares reais.

\section{Agradecimentos}

N.S. agradece aos alunos da disciplina de Processos e Sequências de Ensino e Aprendizagem do polo UFABC do MNPEF por discussões estimulantes e à Débora Coimbra por compartilhar o oferecimento da disciplina em uma das vezes que a ministrei durante minha proveitosa permanência na UFABC. 


\section{Referências}

[1] A.V. Pinto, O conceito de tecnologia (Contraponto, Rio de Janeiro, 2005), v. 1.

[2] A. Zabala, A Prática Educativa: Como Ensinar (Penso, Porto Alegre, 1988).

[3] M. Giordan, Y. Guimarães e L. Massi, Uma análise das abordagens investigativas de trabalhos sobre sequências didáticas: tendências no ensino de ciências, disponível em: http://abrapecnet.org.br/atas_enpec/viiienpec/res umos/R0875-3.pdf

[4] M. Méheut e D. Psillos, International Journal of Science Education 26, 515 (2004)

[5] A.L. Brown e J.C. Campione, em: Innovations in learning: New environments for education, editado por L. Schauble e R. Glaser (Lawrence Erlbaum Associates, Nova Jersey, 1996).

[6] Design-Based Research Collective, Educational Researcher 32, 5 (2003).

[7] S. McKenney e T.C. Reeves, Educational Researcher 42 97 (2013).

[8] F.G. Maciel, M.M. Passos e S.M. Arruda, Revista Brasileira de Pesquisa em Educação em Ciências 18, 549 (2018).

[9] J. Levin e A.M. O'Donnell, Journal of Cognitive Education and Psychology 1, 201 (1999).

[10] P. Lijnse e K. Klaassen, International Journal of Science Education 26, 537 (2004)

[11] A.M.F. Nobre, E.M. Mallmann, I. Martin-Fernades e M.D. Mazzardo, Revista San Gregorio 26, 128 (2017).

[12] F. Kneubil e M. Pietrocola, Investigações em Ensino de Ciências 22, 1 (2017).

[13] J. Leach, J. Ametller e P. Scott, em: Designing theorybased teaching-learning sequences for science education, editado por K. Kortland e K. Klaassen (CDBeta Press, Utrecht, 2010)

[14] J. Guisasola, K. Zuza, J. Ametlle e J. GutierrezBerraondo, Physical Review Physics Education Research 13, 020139 (2017).

[15] T. Anderson e J. Shattuck, Educational Researcher 41, 16 (2012).

[16] A. Bakker e H.A.A. Van Eerde, em: Approaches to Qualitative Research in Mathematics Education, editado por C. Knipping, N.C. Presmeg e A. Bikner-Ahsbahs (Springer Netherlands, Dordrecht, 2015).

[17] R.T. Tamiosso e A.G.S. Pigatto, Revista Educar Mais 4, 156 (2020).

[18] A. Tiberghien, C. Buty e J.F. Le Maréchal, em: Proc. Science and Technology Education at crossroads: meeting the challenges of the 21st century. The second conference of EDIFE and the second IOSTE Symposium in Southern Europe (Athènes, 2005).

[19] A. Tiberghien, J. Vince e P. Gaidioz, International Journal of Science Education 31, 2275 (2009).

[20] C.A.S. Batista e M.R.P. Siqueira, Caderno Brasileiro de Ensino de Física 34, 880 (2017).

[21] A. Tiberghien e M. Barboux, em: Quels types de recherches pour rénover l'éducation en sciences expérimentales, Actes des cinquièmes Journées internationales sur l'éducation scientifique, editado por A. Giordan e J.L. Martinand (UER Didactique, Paris, 1983).

[22] C. Buty, A. Tiberghien e J.F. Le Maréchal, International Journal of Science Education 26, 579 (2004).

[23] J. Leach e P. Scott, Studies in Science Education 38, 115 (2002).

[24] J. Viiri e A. Savinainen, Latin-American Journal of Physics Education 2, 80 (2008).

[25] F. Kabapinar, J. Leach e P. Scott, International Journal of Science Education 26, 635 (2004).

[26] U. Kattmann, H. Gropengießer, R. Duit e M. Komorek, Educational Reconstruction - Bringing together Issues of scientific clarification and students' conceptions. NARST 1996, disponível em: https://bit.ly/3nP2NMv.

[27] R. Duit, H. Gropengießer, U. Kattmann, M. Komorek e I. Parchmann, em: Science Education Research and Practice in Europe: Retrospective and Prospective, editado por D. Jorde e J. Dillon (Sense Publishers, Rotterdam, 2012).

[28] M. Artigue, Grenoble: La Pensée Sauvage-Éditions 9, 281 (1988).

[29] S.A. Almouloud e C. Queiroz-Coutinho, Revemat: Revista Eletrônica de Educação Matemática 3, 62 (2008).

[30] S.A. Almouloud e M.J.F. Silva, Revemat: Revista Eletrônica de Educação Matemática 7, 22 (2012).

[31] M.A. Moreira, Aprendizagem Significativa em Revista 1, 43 (2011).

[32] D.P. Ausubel, The acquisition and retention of knowledge: a cognitive view (Kluwer Academic Publishers, Dordrecht, 2000).

[33] M.A. Moreira, Aprendizagem Significativa: a teoria e textos complementares (LF Editorial, São Paulo, 2011).

[34] M.A. Moreira, Teorias de Aprendizagens (EPU, São Paulo, 1995).

[35] A. Savinainen, A. Mäkynen, P. Nieminen e J. Viiri, Research in Science Education 47, 119 (2017).

[36] J. Leach, J. Ametller e P. Scott, Éducation et didactique 3, 133 (2009).

[37] D. Stavrou, R. Duit e M. Komorek, Physics Education 43, 417 (2008).

[38] I. Arriassecq e I.M. Greca, Science \& Education 21, 827 (2012).

[39] C. Fazio, I. Guastella, R.M. Sperandeo-Mineo e G. Tarantino, International Journal of Science Education 30, 1491 (2008).

[40] M. Pessanha e M. Pietrocola, Revista Brasileira de Educação em Ciências 16, 361 (2016).

[41] F. Savall-Alemany, J. Guisasola, S.R. Cintas e J. Martínez-Torregrosa, Phys. Rev. Phys. Educ. Res. 15, 020138 (2019).

[42] G. Pantoja e M.A. Moreira, Latin-American Journal of Physics Education 11, 1302-1 (2017).

[43] L. Bollen, P. Van Kampen e M. De Cock, Physical Review Physics Education Research 14, 020115 (2018).

[44] G.C. Pantoja e M.A. Moreira, Revista Brasileira de Ensino de Física 42, e20200288 (2020).

[45] G. Vergnaud, Human development 52, 83 (2009). 